\title{
DESIGN, SIMULATION AND HARDWARE IMPLEMENTATION OF EFFICIENT SOLAR POWER CONVERTER WITH HIGH MPP TRACKING ACCURACY FOR DC MICROGRID APPLICATIONS
}

\author{
Vineeth Kumar P. K $\mathbf{1}^{\mathbf{1}}$ Asha C. A A $^{2}$ Sreenivasan M. K \\ ${ }^{l} M$ Tech Student, Electrical and Electronics Engineering, Amrita Vishwa Vidyapeetham, Amritapuri, Kerala, India \\ ${ }^{2}$ Assistant Professor, Electrical and Electronics Engineering, Amrita Vishwa Vidyapeetham Amritapuri, Kerala, India \\ ${ }^{3}$ Instructor, Electrical and Electronics Engineering, Amrita Vishwa Vidyapeetham, Amritapuri, Kerala, India
}

\begin{abstract}
This work includes a high step up voltage gain DC-DC converter for DC microgrid applications. The DC microgrid can be utilized for rural electrification, UPS support, Electronic lighting systems and Electrical vehicles. The whole system consists of a Photovoltaic panel (PV), High step up DC-DC converter with Maximum Power Point Tracking (MPPT) and DC microgrid. The entire system is optimized with both MPPT and converter separately. The MPP can be tracked by Incremental Conductance (IC) MPPT technique modified with D-Sweep (Duty ratio Sweep). D-sweep technique reduces the problem of multiple local maxima. Converter optimization includes a high step up DC-DC converter which comprises of both coupled inductor and switched capacitors. This increases the gain up to twenty times with high efficiency. Both converter optimization and MPPT optimization increases overall system efficiency. MATLAB/simulink model is implemented. Hardware of the system can be implemented by either voltage mode control or current mode control.
\end{abstract}

Keywords: DC microgrid, D-sweep Technique, High step up voltage gain, Incremental Conductance Algorithm (IC), Maximum Power Point Tracking (MPPT), multiple local maxima, Switching losses, tracking accuracy etc.... $* * *$

\section{INTRODUCTION}

The continuous growth of for global energy demand and the environmental concern about the global warming, fossil fuel exhaustion and the need to reduce the carbon dioxide emission has to lead the exploration of renewable energy sources. As compared to other renewable energy sources photovoltaic energy has great advantages like cleanliness, no noise and very less maintenance.

PV systems have been extensively used for low power electrical generation and have applications such as electrification for domestic applications, water pumping and air condition in rural and isolated areas. It is very difficult to establish a new utility system in rural areas because of cost and maintenance consideration. So DC microgrid can be directly used for rural requirements and solar energy can be utilized to generate power. The installed power can be increased by adding panels, which is one of the most attractive features of PV systems. The low conversion efficiency of PV module and the variation of the output power due to changes in atmospheric conditions such as solar irradiation and temperature variation, requires specific control technique to ensure maximum power point operation in order to harvest maximum power from each module. Incremental
Conductance algorithm is used and the power reduction caused by the shadow effect is overcome by adding D-sweep technique in the MPPT control algorithm. A DC-DC converter with high voltage gain is employed to step up the output DC voltage from the PV module to a high voltage level without losing the overall efficiency of the system.

The solar power converter [1] is used as a DC-DC converter which harvest maximum energy from each individual PV module. This converter with MPPT increases the PV panel voltage to a higher voltage level as required by the DC microgrid. Fig. 1 shows the basic representation of the proposed system.

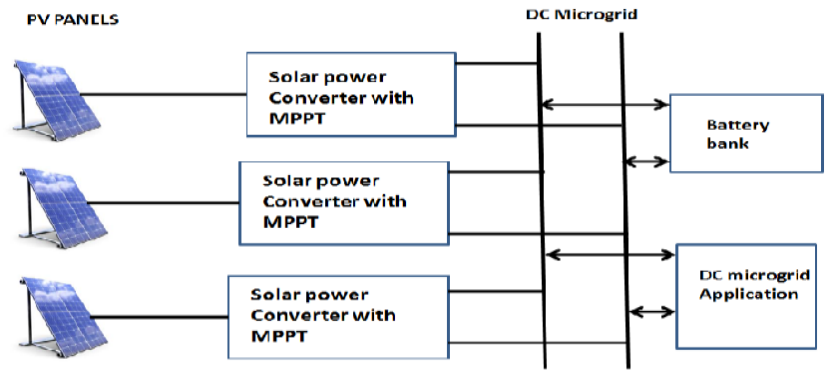

Fig 1 General block diagram of the system 
A 400V DC microgrid is used for DC microgrid applications. The converter is basically a non inverted sepic. It is also similar to the combination of conventional buck boost with coupled inductor and switched capacitors. The overall system efficiency is increased by the converter optimization as well as MPPT optimization [2]. The converter optimization includes a coupled inductor and switched capacitors which reduces switching losses and increased overall system efficiency. The switching losses are reduced by recycling leakage inductance energy. The switched capacitors increases voltage gain up to 20 times with high efficiency. The MPP optimization includes incremental conductance algorithm with $\mathrm{D}$-sweep technique [3] which helps to reduce the effect of partial shading. Thus the overall efficiency of the PV system is increased.

Section 2 explains System Description, Section 3 describes MPPT Control, Section 4 describes Voltage Mode Control, Section 5 includes Design of Proposed System, Section 6 describes Simulation Results and Section 7 Concludes the paper.

\section{SYSTEM DESCRIPTION}

The overall system consists of PV panels, High Step up Solar Power Converter, DC microgrid and Battery Bank. DC microgrid provides various applications such as UPS Support, Electronic Lighting etc. Each part is explained individually in the system description.

\subsection{Introduction to System Analysis}

The whole system for DC microgrid applications is divided into the following subsections such as PV panels, High Step up Solar Power Converter, Incremental Conductance algorithm with D-sweep technique, DC microgrid and its control part. Explanation of each part is given below.

\subsection{Solar PV Panels}

Basically, solar cell is a semiconductor material. It consists of both $\mathrm{P}$ and $\mathrm{N}$ junction which form a PN junction. The working principle of solar cell is the principles of Photovoltaic effect. Representation of PV cells is shown in the fig. 2.

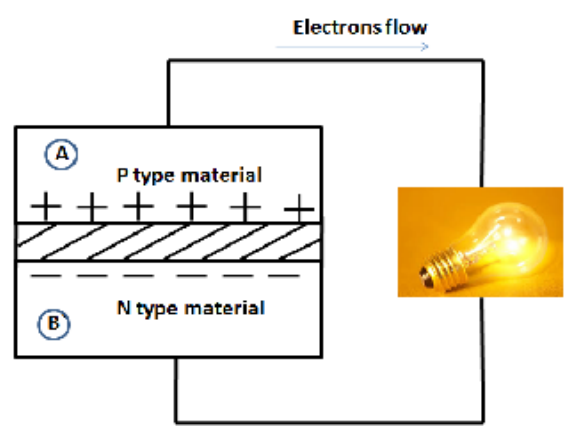

Fig 2 Representation of working principle of PV cells
Material A consists of P type material and material B consists of $\mathrm{N}$ type materials. $\mathrm{P}$ junction consists of holes and $\mathrm{N}$ junction consists of electrons. In $\mathrm{P}$ junction holes are the majority carriers and electrons are the minority carriers. Similarly in $\mathrm{N}$ junction electrons are the majority carriers and holes are the minority carriers. Combining two junctions forms a PN junction diode.

\subsection{High Gain Solar Power Converter}

The converter used here is a high step up and high voltage gain DC-DC converter. Basically the DC-DC converter mentioned in this work is a non inverted Sepic converter. It shows the similarity to the modified buck boost topology [6][9]. The converter has both coupled inductor and switched capacitors. By using a diode and a capacitor, the leakage inductance energy from the coupled inductor is recycled. So that switching loss is reduced up to a limit. Similarly the switched capacitors helped to increase the voltage gain up to 20 times with $95 \%$ of system efficiency. Presence of switched capacitors the voltages are adding serially to get DC grid voltage requirements. The solar power converter is working based on the combination of continuous, discontinuous and boundary conduction modes. Each mode is divided into five sub intervals. The importance of power converter is represented in Fig. 3. It gives the idea about the solar power converter in the overall system. The high step up solar power converter circuit is represented in Fig. 4.

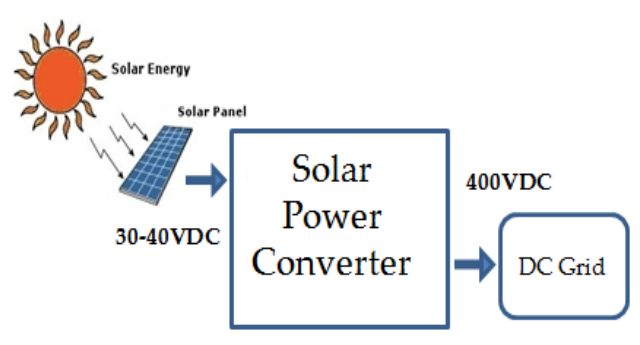

Fig. 3. Basic block diagram of the system

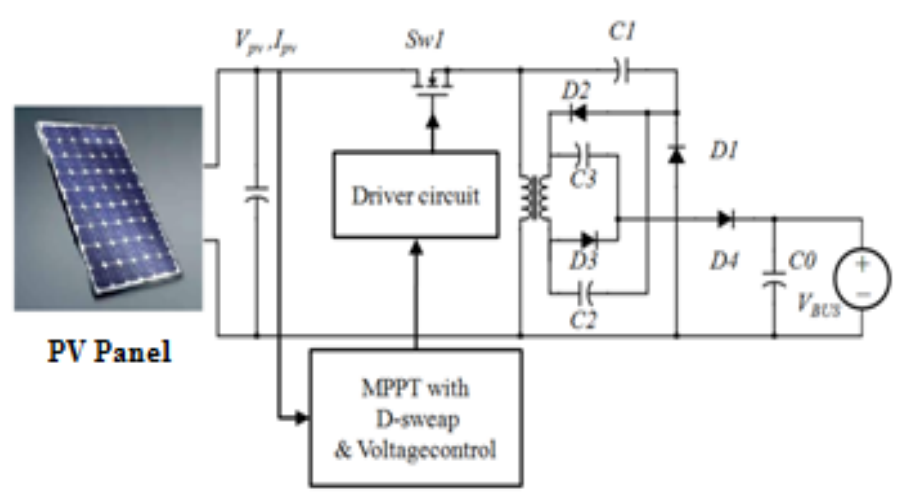

Fig 4 Power Converter Circuit diagram 
The switch Sw1 is a high side switch i.e., the source terminal is not directly connected to the ground. The coupled inductor $\mathrm{N} 1$ is similar to the input inductor of the conventional buck boost converter. Both $\mathrm{N} 1$ and $\mathrm{N} 2$ represent the coupled inductors. The Capacitors $\mathrm{C} 2$ and $\mathrm{C} 3$ are called switched capacitors. Switched capacitors $\mathrm{C} 2$ and $\mathrm{C} 3$ are connected with the diodes D2 and D3. The diode D4 is rectifying diode which is connected to the output capacitor $\mathrm{C} 0$ and $\mathrm{DC}$ bus. Recycling the leakage inductance energy from coupled inductor $\mathrm{N} 1$ to capacitor $\mathrm{C} 1$ and diode D1 will reduce the voltage stress and switching losses across the high side floating active switch. Solar panel DC link with converter has decoupling capacitor $\mathrm{C} 0$. Decoupling capacitor provides fast switching surges. The modified MPPT algorithm works based on $\mathrm{V}_{\mathrm{PV}}$ and $\mathrm{I}_{\mathrm{PV}}$. This will determine either increase or decrease in the duty ratio. The MPP can be obtained by comparing instantaneous conductance and incremental conductance.

\section{MPPT CONTROL}

MPPT is a control algorithm which keeps the duty ratio in a specific value and by the value power from the PV panel will be extracted maximum. Power from the PV panel varies in accordance with solar irradiation, ambient condition and temperature. Similarly the electrical characteristics vary from the each solar cell. Incremental Conductance algorithm, P\&O method, Hill climbing algorithm etc. are the important MPPT technique. During fast changing irradiance conditions and partial shading the incremental conductance algorithm is optimized MPPT in the proposed system. A portion of solar panel is shaded by any factors such as tree, building, clouds etc. cause partial shading. As a result, a portion of PV panel is separated by shadow and more current will flows through the unshaded portion. Therefore electrical characteristics of PV panel will be altered and causes damage to the PV panel. In order to avoid the shadow effect up to a limit, Incremental Conductance algorithm with D-sweep (Duty ratio-sweep) is introduced [4].

Incremental conductance locates maximum power when the incremental conductance equal to the negative of instantaneous conductance. Mathematically the condition for maximum power can be derived with the help of a PV curve shown in the fig. 5. Let $\mathrm{P}$ be the power from the PV panel and $\mathrm{V}$ be the PV panel voltage. Applying the principle of maximaminima i.e. the rate of change of power with respect to PV panel voltage is equated to zero.

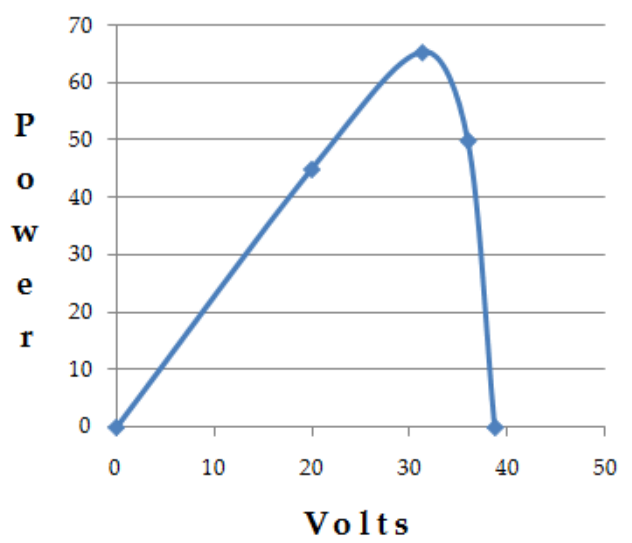

Fig 5 PV curve of a solar panel

We have $\mathrm{dP} / \mathrm{dV}=0$ and $\mathrm{d}(\mathrm{V} * \mathrm{I}) / \mathrm{dV}=0$. Solving the mathematical conditions such as

$$
\mathrm{dI} / \mathrm{dV}=-\mathrm{I} / \mathrm{V}
$$

Here $\mathrm{d} / \mathrm{dV}$ represent as incremental conductance and negative $(-\mathrm{I} / \mathrm{V})$ represents instantaneous conductance. The equation (1) represents the condition for maximum power. The Incremental Conductance [7]-[8] uses a search technique that changes a reference or duty ratio. So that $\mathrm{Vpv}$ changes searches for the condition of the equation and in the condition the maximum power point is found and searching will stop. The incremental conductance algorithm continues to calculate dIpv until the result is no longer to zero. At the time search started again. Incremental conductance algorithm is best suited for the rapidly varying irradiation conditions.

The left portion of the PV curve has a positive slope. Here the Incremental conductance greater than instantaneous conductance. If a point corresponding to power lies anywhere in the left portion of PV curve, the voltage should increase to reach maximum power point. Thus the duty ratio of the converter is reduced and maximum power point is reached. Similarly, if a point corresponding to power is located anywhere on the right side of maximum power point, the voltage must reduce and corresponding duty ratio increased to reach maximum power point.

The local multiple maxima is one of the serious affect partial shading. Therefore incremental conductance algorithm fails to find the maximum power. It is difficult to find out the maximum power point from the number of different multiple local maxima. To solve this problem D-sweep technique is suggested with incremental conductance algorithm. In Dsweep method, finding different power at different duty ratios and comparing those powers to get larger value and corresponding duty ratio. Use some duty ratio as the starting point of incremental conductance algorithm. The minimum and maximum duty ratio for D-sweep is kept for the range of 
30 and $40 \mathrm{~V}$ as per the PV panel test. The maximum and minimum duty ratio is chosen as that which can avoid unnecessary power losses and heating of the devices.

The sweep is varied from Dmin to Dmax during initial step. After the sweep, the incremental conductance MPPT works effectively. The suggested flow chart of D-sweep technique is shown in Fig. 6. The first step is to increment the duty ratio. The next step is to measure present power. Compare the present power with the last power. Store the larger power. Thus D-sweep can reduce the problem of multiple local maxima during partial shading condition.

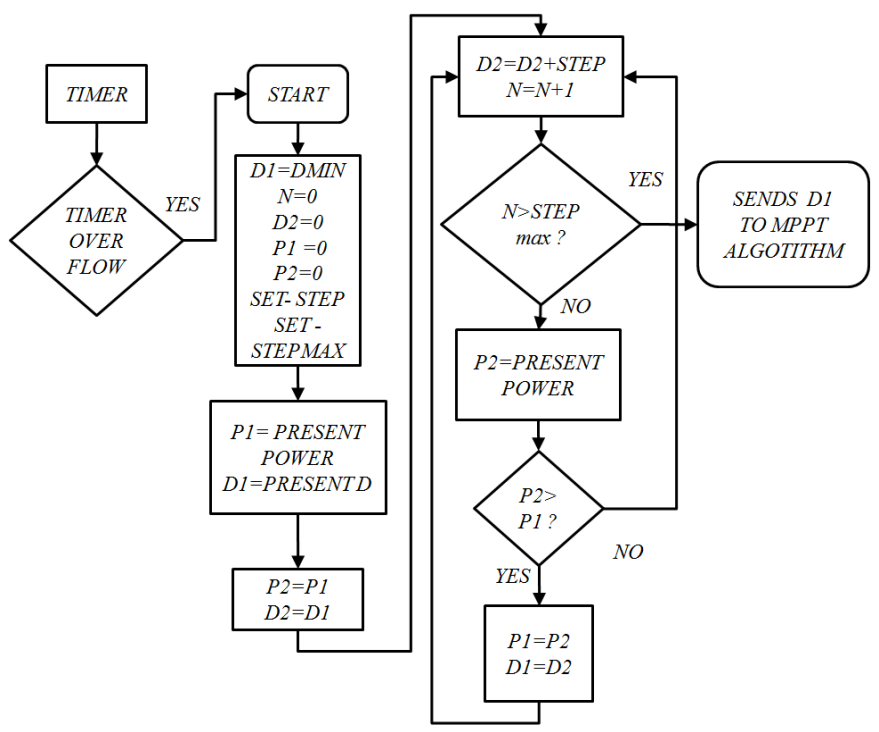

Fig 6 D-sweep technique

\section{VOLTAGE MODE CONTROL}

The requirement of DC grid voltage is $400 \mathrm{~V}$ the output of the converter is fed to the DC microgrid. The electrical energy can directly take from the DC microgrid. Battery tank stores the excess energy available from the Solar PV panel.

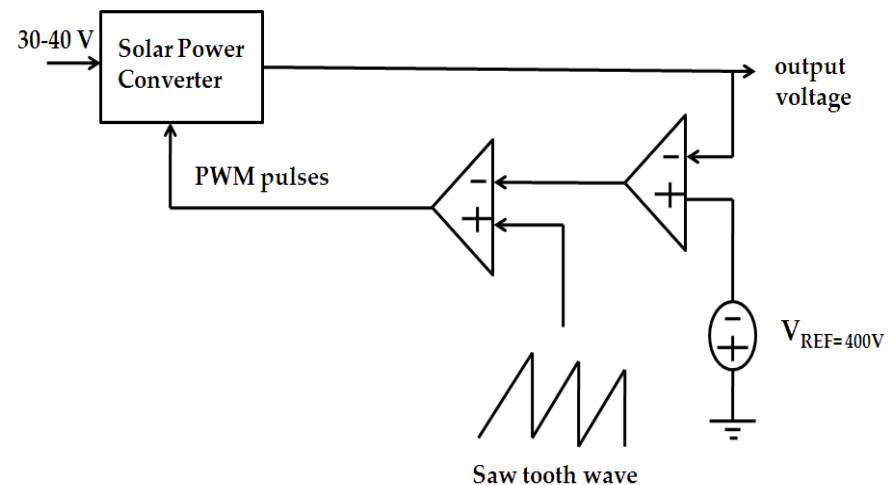

Fig 7 Voltage mode control
It shouldn't be more or less than $400 \mathrm{~V}$. Voltage mode control maintains the DC grid voltage at $400 \mathrm{~V}$. In order to maintain stability, the DC microgrid voltage [5] should be 400V. The fig.7. represents the general block diagram of voltage mode control.

The reference voltage is set to $400 \mathrm{~V}$. The output of error amplifier is applied to comparator. The output of comparator is PWM having the system frequency, which is fed to the gate of MOSFET shown in the fig. 7 .

\section{DESIGN OF PROPOSED SYSTEM}

The proposed system supports DC microgrid applications directly. The PV panel capacity of the proposed system is $250 \mathrm{~W}$. DC grid voltage requirement is $400 \mathrm{~V}$. The input voltage available from the PV panel varies from $30-40 \mathrm{~V}$. The system parameters are given below in the table 1 .

Table -1: System Parameters

\begin{tabular}{|l|l|}
\hline Full PV output power available & $250 \mathrm{~W}$ \\
\hline Available input voltage minimum & $30 \mathrm{~V}$ \\
\hline Output voltage & $400 \mathrm{~V}$ \\
\hline Switching frequency & $50 \mathrm{kHz}$ \\
\hline
\end{tabular}

The system parameters specified here are suitable for both simulation and hardware implementation. The MATLAB/Simulink tool is used for simulation analysis. The design of converter parameters are included in the Table 2.

Table -2: Converter Parameters

\begin{tabular}{|c|c|c|c|}
\hline Gain & Voltage Gain & $\frac{V_{0}}{V_{i n t}}=\frac{(n \cdot D+n+1)}{(1-D)}$ & 13.33 \\
\hline$n$ & Turns Ratio & 4 is the better choice & 4 \\
\hline$D$ & Duty Ratio & & $48 \%$ \\
\hline$T_{L m B}$ & $\begin{array}{l}\text { Magnetization } \\
\text { Time Constant }\end{array}$ & $\frac{D(D-1)^{2}}{2(2 n+1)(n D+n+1)}$ & $1.042 \times 10^{-3}$ \\
\hline $\mathrm{Lm}$ & $\begin{array}{l}\text { Magnetization } \\
\text { Inductance }\end{array}$ & $\begin{aligned} T_{\text {LnB }} \cdot R \cdot T_{S}= & 1.042 \times 10^{-3} \times 0.640 \\
& \times 20 \times 10^{-3}\end{aligned}$ & $13.3 \times 10^{-6} \mathrm{H}$ \\
\hline
\end{tabular}

Best choice of selection of turns ratio is 4 . It is obtained by trial and error method. Found out the duty ratio corresponding to each turns ratio. Finally selected the turns ratio as four. Calculated the value of magnetization inductance based on the equation shown in the Table 2. The Table 3 gives the calculation of leakage inductance in the coupled inductor. The calculation of switched capacitors based on the set of equations shown in the Table 3 . The switched capacitors have a vital role in increasing the voltage gain up to 20 times. 
Table -3: Calculation of Leakage Inductance

\begin{tabular}{|c|c|c|}
\hline$L 2$ & $\frac{n 1}{n 2}=\sqrt{\left(\frac{L 1}{L 2}\right)} \quad ; L 1=L_{m}$ & $442 \mu \mathrm{H}$ \\
\hline$L_{k 2}$ & $1 \%$ of $L 2$ & $4.42 \mu \mathrm{H}$ \\
\hline$L_{k j}$ & $1 \%$ of $L 1$ & $0.27656 \mu \mathrm{H}$ \\
\hline
\end{tabular}

The design of switched capacitor is crucial in the case of high step up solar power converter. C2 and C3 are the switched capacitors. The design of capacitors is explained in Table 4.

Table -4: Design of Capacitors

\begin{tabular}{|c|c|c|}
\hline C1 & lo.Ts/DeltaVc1=(0.625X20us)/(27.69X.02) & 22.57 uF \\
\hline C2=C3 & Io.Ts/delta.Vc2 $=(0.625 \times 20 u s) /(2.21)$ & $5.65 u F$ \\
\hline Co & lo.D.Ts/DeltaVo=(0.625X0.48X20uS)/8 & $0.75 \mathrm{uF}$ \\
\hline
\end{tabular}

The first step of hardware implementation is the selection of components. Based on the requirements of the system the components are selected. IRFP250N is the selected switch. It is an $\mathrm{N}$ channel MOSFET. The diodes D1, D2, D3 and D4 are selected based on the voltage and power ratings. MUR 1560 is suitable for the proposed system. The components selection is listed in the Table 5 and Table 6.

Table -5: Components Selection for Hardware

\begin{tabular}{|c|c|c|}
\hline Components & $\begin{array}{c}\text { Voltage } \\
\text { across }\end{array}$ & $\begin{array}{c}\text { current } \\
\text { though }\end{array}$ \\
\hline $\begin{array}{c}\text { IRFP250N MOSFET } \\
\text { Switch }\end{array}$ & $110 \mathrm{~V}$ & $30 \mathrm{~A}$ \\
\hline Diode D1- MUR 1560 & $110 \mathrm{~V}$ & $20 \mathrm{~A}$ \\
\hline Diode D2-MUR 1560 & $350 \mathrm{~V}$ & $1.6 \mathrm{~A}$ \\
\hline Diode D3-MUR 1560 & $91 \mathrm{~V}$ & $2 \mathrm{~A}$ \\
\hline Diode D4-MUR 1560 & $280 \mathrm{~V}$ & $7 \mathrm{~A}$ \\
\hline $\begin{array}{c}\text { Decoupling capacitor } \\
76 \mathrm{~V}\end{array}$ & $-20 \mathrm{~A}$ \\
\hline $\begin{array}{c}\text { Switched capacitors } \\
\text { (C2 \& C3) }\end{array}$ & $90.8 \mathrm{~V}$ & $7 \mathrm{~A}$ \\
\hline Capacitor C4 & $418 \mathrm{~V}$ & $6 \mathrm{~A}$ \\
\hline
\end{tabular}

The MUR1560 is selected based on both voltage and power dissipation factors. The heat sink selection is very important in hardware implementation. After calculating the core area, E55 core is selected for the coupled inductor.

Table -6: Selection of Diode Based on Power Dissipation

\begin{tabular}{|l|c|}
\hline COMPONENTS & Power Dissipation \\
\hline Diode D1 & 0.8 Watts \\
\hline Diode D2 & 0.8 Watts \\
\hline Diode D3 & 0.8 Watts \\
\hline Diode D4 & 0.8 Watts \\
\hline
\end{tabular}

Depending upon the current carrying capacity 22 SWG cable is selected for winding coupled inductor. Enameled copper wire is used for the winding. There will be large difference in voltage between the primary as well as secondary of the coupled inductor. The large difference in voltage may result in arcing. The Mylar sheet provides proper isolation between primary and secondary. It will prevent the arcing phenomenon between primary and the secondary of the coupled inductor. LCR meter is used for measuring the inductance of coupled inductor. The calculated primary inductance of coupled inductor is $27.6 \mathrm{uH}$ and the secondary inductance is $441 \mathrm{uH}$. The real value of primary inductance from the LCR meter is $28.6807 \mathrm{uH}$ and the secondary inductance is $485.641 \mathrm{uH}$. Hence the coupled inductor design is verified. The experimental set up of coupled inductor design is shown in the fig. 8 .
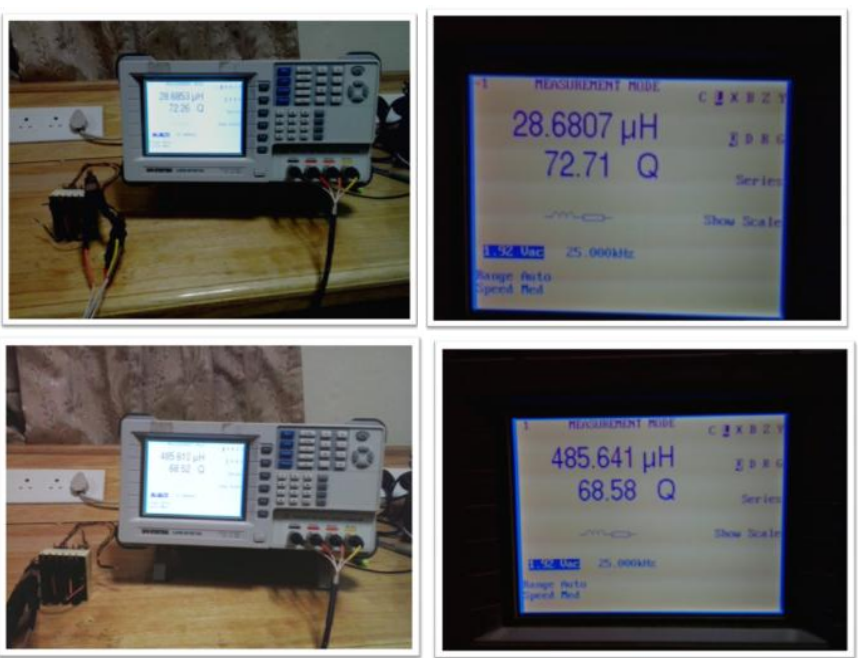

Fig 8 Coupled Inductor winding and Design verification

Heat sink for the system is selected. Heat sink selection is based on the device dissipating heat into the surrounding air. The maximum surface area should contact with the surrounding for the proposed power circuit. Selected a plane 
board for assembling power circuit and control circuits. Heat sink is fixed on the main board as shown in the fig. 9 .

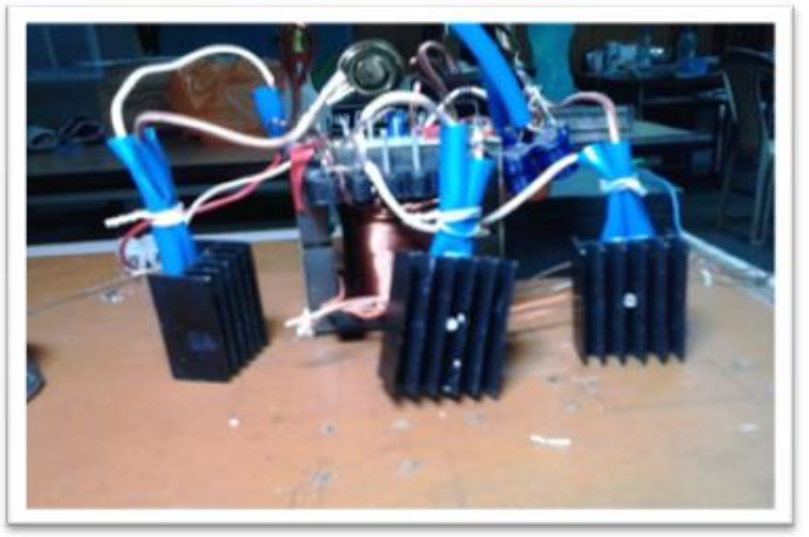

Fig 9 Heat sink selection and assembly of the components

A microcontroller is used for generating the PWM pulses having a frequency of $50 \mathrm{kHz}$. AVR Atmega 8 is selected for basic PWM generation having $50 \mathrm{kHz}$ switching frequency. AVR programming is used for generating PWM for the requirement of the system. WinAVR is installed in the computer, coding is completed and verified the burning procedure. The circuit arrangement for the PWM generation is shown in the fig. 10.

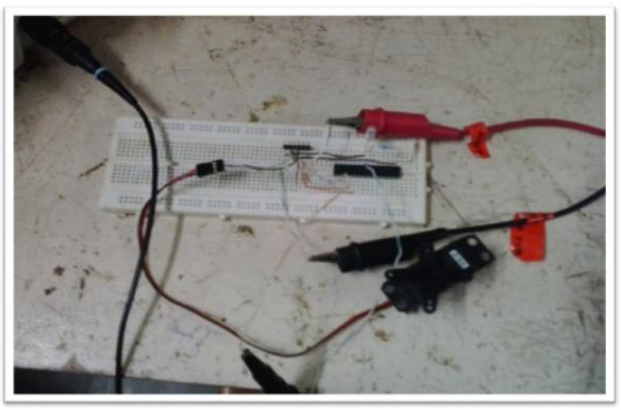

Fig 10 Microcontroller Circuit for PWM Generation

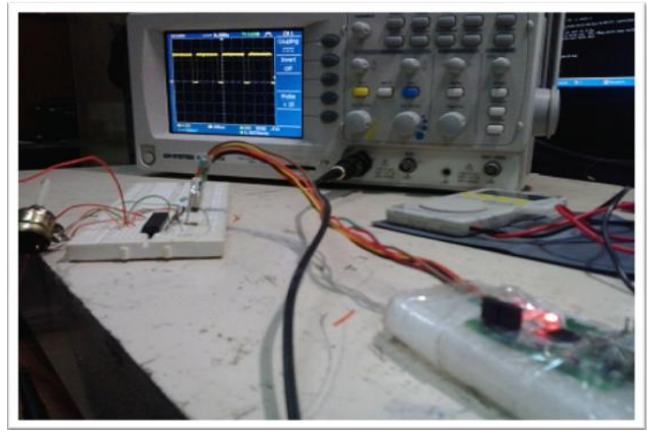

Fig 11 Experimental set up for PWM Generation

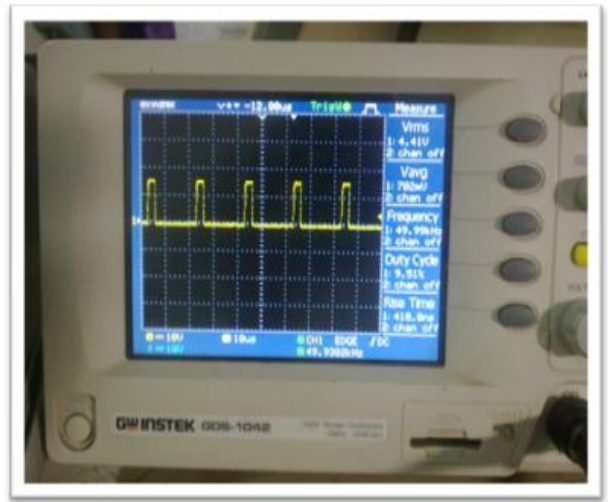

Fig 12 PWM Output using DSO

\section{SIMULATION RESULTS}

MATLAB/Simulink environment is used for the simulation of the proposed system. Modeled and analyzed the PV panel by using the MATLAB simulation. Mainly converter part is concentrated for the whole system. Incremental conductance MPPT is verified in the whole system and the tracking has verified. The simulink model is shown in the fig. 13.

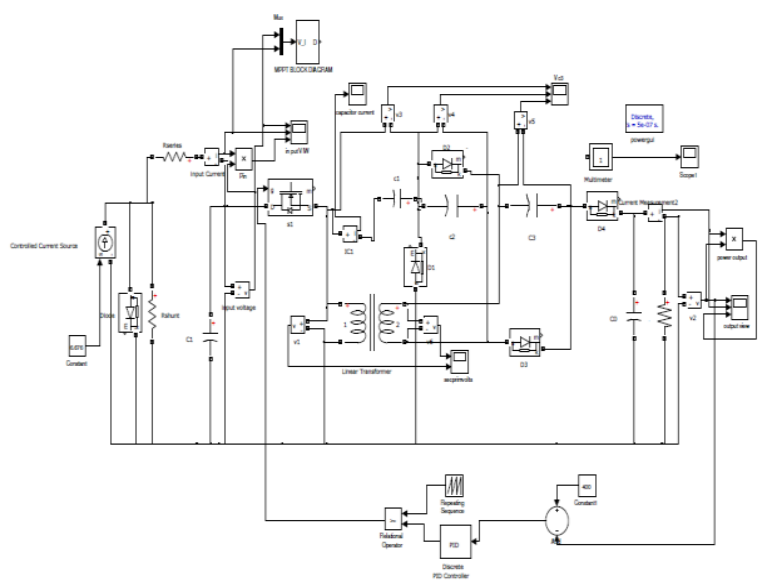

Fig 13 Simulink Model of Solar Power Converter

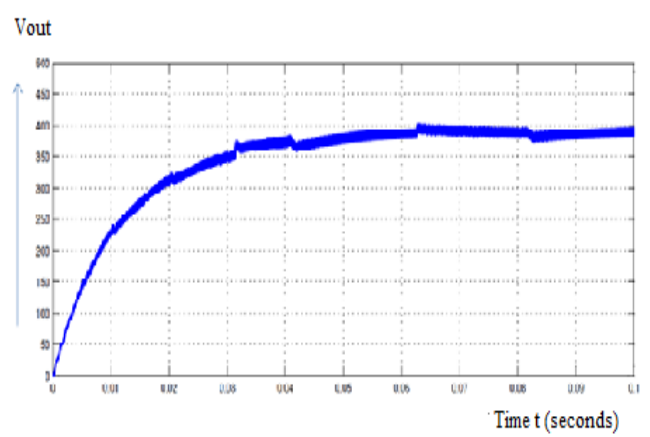

Fig 14 Output Voltage of Solar Power Converter 
The output voltage of the solar power converter obtained is $400 \mathrm{~V}$ which is shown in the fig. 14. The input voltage is varied from $20 \mathrm{~V}$ to $40 \mathrm{~V}$. Input current ranges from $6 \mathrm{~A}$ to $7 \mathrm{~A}$. Output current ranges from $0.5 \mathrm{~A}$ to $0.8 \mathrm{~A}$. The output of the Solar Power Converter is fed to the DC grid. DC grid voltage is maintained to $400 \mathrm{~V}$ by using Voltage mode control [9]. So that output voltage keeps $400 \mathrm{~V}$, whatever the input voltage. Thus maintains the stability of the system.

The fig. 15 shows efficiency versus time plot of the system. The efficiency obtained in the solar power system is $95 \%$. Thus output of solar power converter is fed to DC microgrid with high efficiency. Voltage gain obtained is 11 .

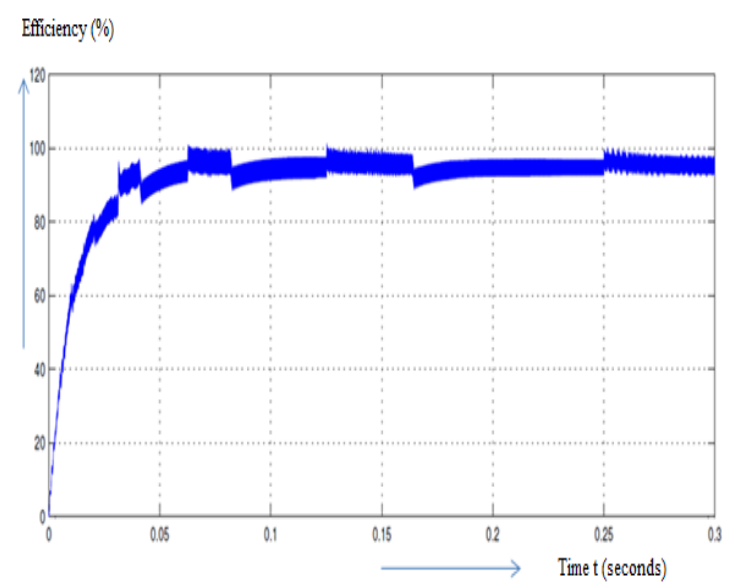

Fig 15 Efficiency of the Solar Power Converter

The proposed converter can boost the voltage to a high voltage level without losing the overall efficiency. The main reason for increasing the overall efficiency is optimization [10]. Due to optimization both the switching losses and voltage stress is reduced up to a limit. Definitely, the DC microgrid can be utilized for various applications such as UPS support, electronic lighting etc.

\section{CONCLUSIONS}

The solar power converter used for the DC microgrid application shows the overall efficiency of $95 \%$ with high voltage gain of 11 . The output of solar power converter fed to DC microgrid can be utilized for various applications such as UPS support, Electronic lighting and Electrical vehicle systems. Converter optimization and MPP optimization increased overall efficiency of the system. The output voltage obtained is $400 \mathrm{~V}$ with high efficiency. The voltage mode control is applied to control the DC grid voltage of the value of 400V. Simulation result of the system is verified. As of now, initial steps for hardware implementation are started. The whole system can be utilized for the DC microgrid application and it will be one of the sustainable developments in the energy field.

\section{ACKNOWLEDGEMENTS}

A special thanks to Dr. Manjula G Nair, Professor, Department of Electrical and Electronics Engineering, Amrita Vishwa Vidyapeetham University, Amritapuri Campus, Kollam, Kerala, India. Her valuable suggestions and comments helped us to complete this work.

\section{REFERENCES}

[1]. Shih-Ming(Orion), Chen,Tsorng-Juu(Peter), Liang, and $\mathrm{Ke} \mathrm{RenHu}$, "Design, Analysis, and Implementation of Solar Power Optimizer for DC Distribution System", IEEE transactions on power electronics, vol. 28, No. 4, pp17641772, April 2013

[2]. S. Jain, V. Agarwal. "A New Algorithm for Rapid Tracking of Approximate Maximum Power Point in PhotovoltaicSystems",IEEEPower Electronics Letters, vol.2, no.3, pp. 16-19, 2004.

[3]. M. Sokolov and D. Shmilovitz, "A modified MPPT scheme for accelerated convergence," IEEE Trans. Energy Convers., vol. 23, no. 4, pp. 1105-1107, Dec. 2008.

[4]. Vineeth Kumar P. K., Asha C. A., "An Efficient Solar Power Converter with High MPP Tracking Accuracy for Rural Electrification", submitted for publication.

[5]. Bo Yang, Wuhua Li, Yi Zhao, Xiangning He, "Design and analysis of a grid-connected photovoltaic power system," Power Electronics, IEEE Transactions on , vol.25, no.4, pp.992-1000, April 2010.

[6]. G.R. Walker and P.C. Sernia, "Cascaded DC-DC converter connection of photovoltaic modules," IEEE Trans. Power Electron., vol. 19, no. 4,pp. 1130-1139, July 2004.

[7]. J. H. R. Enslin, M. S. Wolf, D. B. Snyman, and W. Swiegers, "Integrated Photovoltaic Maximum Power Point Tracking Converter," in IEEE Transactions on Industrial Electronics, vol. 44, 1997, pp. 769 - 773.L. Hubert and P. Arabie, "Com ping Partitions," J. Classification, vol. 2, no. 4, pp. 193-218, Apr. 1985

[8]. Geun Kim, "Maximum Power Point Tracking Controller Connecting PV System to Grid", Journal of Power Electronics, Vol. 6, No. 3, July 2006, pp. 226234.

[9]. J. Gow and C.Manning, "Photovoltaic converter system suitable for use in small scale stand-alone or grid-connected applications," IEE Proc.-Electr. Power Appl., vol. 147, no. 6, pp. 535-543, Nov. 2000.

[10]. The Solar Design Company. $P V * S O L$ (2012). [Online]. Available: http://www.solardesign.co.uk/pv.php/

\section{BIOGRAPHIES}

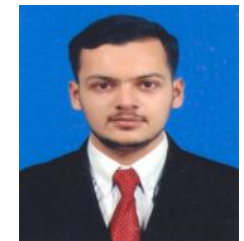

Vineeth Kumar P. K. was born in kannur, kerala. He received his B.Tech degree in Electrical and Electronics Engineering from Vimal Jyothi Engineering College, Chemperi, Kannur University, India in 2011 and Currently he is doing M.Tech in Power and Energy Engineering at Amrita Vishwa vidyapeetham 
University, Amritapuri campus, Kollam, Kerala, India. His areas of interests are renewable energy sources, power converters, DC machines and power systems.

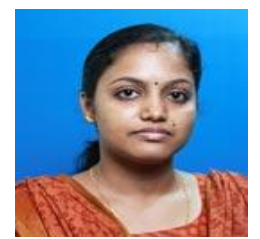

Asha C. A. currently working as Assistant professor in the department of Electrical And Electronics Engineering, Amrita Vishwa Vidyapeetham university, Amritapuri Campus, Kollam, Kerala, India. She graduated in Electrical and Electronics Engineering from Lourdes Matha College of Science and Technology, Kuttichal, Thiruvananthapuram and post graduated in Electrical Machines from College of Engineering Trivandrum, Kerala, India in the year 2009 and 2012 respectively. Her areas of interests are electrical machines, power systems and renewable energy sources.

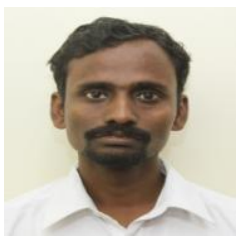

Sreenivasan M. K currently working as Instructor at Robotic Lab in the Department of Electrical and Electronics Engineering, Amrita Vishwa Vidyapeetham, Amritapuri Campus, Kollam, Kerala, India $\mathrm{He}$ has seven years of experience at Amrita Vishwa Vidyapeetham University and handled several projects in the areas of Power Electronics and Robotics. His areas of interests are power electronics, Robotics and Embedded systems. 